\title{
Giro a la izquierda en la América Latina del siglo XXI. Revisitando los debates académicos
}

\author{
Soledad Stoessel \\ Universidad Nacional de La Plata, La Plata, Argentina \\ Email: soledadstoessel@yahoo.com.ar
}

\begin{abstract}
Resumen: El "giro a la izquierda" de gran parte de los gobiernos latinoamericanos durante el siglo XXI colocó a las ciencias sociales frente al desafío de analizar las especificidades que asumieron los procesos políticos contemporáneos. La literatura al respecto privilegió, a grandes rasgos, el estudio de dos aspectos transversales a las vigentes experiencias políticas: los contenidos de las agendas post-Consenso de Washington y la recuperación de las capacidades estatales. De este modo, la idea de postneoliberalismo y el llamado "retorno del Estado" aparecen como elementos insoslayables de diferentes interpretaciones conceptuales y análisis políticos. En este sentido, este artículo procura ofrecer una revisión de la literatura especializada a partir de estas dimensiones que configuraron el fenómeno latinoamericano desde inicios de este siglo.
\end{abstract}

Palabras clave: izquierdas, América Latina, post-neoliberalismo, Estado.

\section{Latin America's left turn in the twenty-first century. Revisiting the academic debates}

\begin{abstract}
The "turn to the left" of most of Latin American governments during twenty-first century challenged social sciences to analyze the specific characteristics of these contemporary political processes. The literature on the subject privileged, broadly speaking, the study of two cross-wise aspects of current political experiences: the contents of their post-Washington Consensus agendas and the recovery of state's capacities. Thus, the postneoliberalism idea and the socalled "state return" emerged as unavoidable elements of different conceptual interpretations and political analysis. In this way, this article aims to provide a revision of specialized literature from these two dimensions which have configured the Latin American phenomena since the beginning of this century.
\end{abstract}

Key words: lefts, Latin America, postneoliberalism, State.

\section{Giro à esquerda na América Latina do século. Revisitando os debates acadêmicos ${ }^{1}$}

Resumo: O "giro à esquerda" da maioria dos governos latino-americanos durante o século XXI colocou às ciências sociais perante o desafio de analisar as especificidades que assumiram os processos políticos contemporâneos. A literatura respectiva privilegiou, em termos gerais, o estudo de duas questões transversais às vigentes experiências políticas: os conteúdos das agendas pós-Consenso de Was- 
hington e a recuperação das capacidades do Estado. Assim, a ideia do pósneoliberalismo e o chamado "retorno do Estado" surgem como elementos essenciais de diferentes interpretações conceituais e análises políticos. Neste sentido, este artigo tem como objetivo apresentar uma revisão da literatura especializada a partir destas dimensões que moldaram o fenômeno latino-americano desde o início deste século.

Palavras-chave: esquerda, América Latina, pós-neoliberalismo, Estado

\section{Introducción}

Como tantos otros debates en el marco de las ciencias sociales, el "giro a la izquierda” de gran parte de los gobiernos latinoamericanos durante el siglo XXI suscitó incansables discusiones académicas y diversas querellas políticas en distintas partes del globo. La emergencia de experiencias políticas progresistas en países como Argentina, Bolivia, Brasil, Chile, Ecuador, El Salvador, Guatemala, Nicaragua, Paraguay, Uruguay y Venezuela ${ }^{2}$ colocó a la academia frente al desafío de pensar y analizar los rasgos y especificidades que asumieron los procesos políticos contemporáneos. Hacia el año 2008, once de los dieciocho países latinoamericanos eran gobernados por presidentes de centro-izquierda o izquierda (Stokes, 2009). En este sentido, infinita cantidad de hojas fueron destinadas a reconstruir, analizar y comprender las múltiples y complejas experiencias políticas de buena parte de los países gobernados por coaliciones, movimientos o partidos políticos progresistas. No obstante, y si bien la idea del "giro a la izquierda” constituye ya un "lugar común” (Arditi, 2009) como marco general de cualquier debate y discusión preocupados por el estudio de los gobiernos latinoamericanos contemporáneos, pocos trabajos sistematizaron la copiosa literatura desarrollada a propósito de esta temática ${ }^{3}$.

Pese a la heterogeneidad de perspectivas y enfoques que se elaboraron para realizar aportes teórico-conceptuales y estudios empíricos, todos, en mayor o menor medida, privilegiaron el análisis de dos aspectos transversales a los vigentes procesos políticos: los contenidos de sus agendas políticas orientadas a quebrar los postulados centrales del Consenso de Washington y la recuperación de las capacidades estatales. De esta forma, la idea de postneoliberalismo y el llamado “retorno del Estado" aparecen como elementos insoslayables de diferentes interpretaciones conceptuales y análisis políticos acerca de los procesos de cambio político de América Latina. La discusión acerca de la naturaleza de las fuerzas políticas gubernamentales, las continuidades y rupturas que cada experiencia implicaba con el modelo neoliberal, sus compromisos con el régimen democrático y las especificidades que las volvían diferentes entre sí monopolizaron el debate de los últimos diez años en la región ${ }^{4}$.

En este contexto, el artículo procura ofrecer una revisión de la literatura especializada que se ha desarrollado en torno al "giro a la izquierda” en 
América Latina suscitado desde principios de este siglo. Esta exploración no pretende agotar el campo de estudio del problema del "giro a la izquierda"-ejercicio de sobra ambicioso, considerando la multiplicidad de aristas, disciplinas y perspectivas a partir de las cuales se analizó el fenómeno-, sino ordenar y sistematizar el complejo y entreverado debate a partir de las dos dimensiones señaladas. El trabajo se estructura en dos grandes secciones. En primer lugar, se abordará el debate generado alrededor de la naturaleza y rol de las izquierdas contemporáneas en las vigentes experiencias políticas a partir de la tesis de "las dos izquierdas" que circuló en diversos espacios académicos y políticos. En segundo lugar, se presentarán las diversas vías y estrategias que operaron en los procesos de cambio político para enfrentar las consecuencias -sociales, políticas y económicas- del modelo neoliberal de las décadas previas. En este apartado, se hará hincapié en las querellas conceptuales en torno a la categoría tan discutida de "postneoliberalismo" y en los principales aspectos del debate acerca del “retorno del Estado". Por último, a modo de cierre, se presentarán algunas tensiones que atraviesan a los debates actuales en torno a los actuales gobiernos latinoamericanos.

\section{Las izquierdas latinoamericanas en el poder político}

Cuando en 2006 apareció un artículo del por entonces canciller mexicano Jorge Castañeda en el que sostenía provocativamente que los procesos políticos latinoamericanos estaban liderados por dos izquierdas bien diferenciadas, una constelación de trabajos se extendieron para reafirmar o discutir dicho postulado. No hubo artículo académico (e incluso debate político) que, directa o indirectamente, no hiciera alusión a la tesis propuesta por Castañeda según la cual desde principios de este siglo (en estricto rigor, desde 1999 con el ascenso de Hugo Chávez al poder político en Venezuela) en la región gobiernan dos tipos de izquierda. Por un lado, una "moderna, abierta y reformista" -representada por los gobiernos de Lagos y Bachelet en Chile, de Vázquez en Uruguay y en menor medida, de Lula da Silva en Brasil- y, por otro lado, una "nacionalista, estridente y cerrada"representada por los gobiernos de Morales en Bolivia, Correa en Ecuador y Chávez en Venezuela (2006: 29), colocando a los gobiernos argentinos de Kirchner y Fernández en una posición ambigua o intermedia (Moreira et al., 2008; Weyland, 2009).

No obstante su escaso aporte para el estudio riguroso de los fenómenos contemporáneos -dadas sus pretensiones más normativas que analítico-explicativas- esta polémica tesis contribuyó a generar la discusión en torno al tan pregonado "giro a la izquierda": ¿de qué naturaleza son los procesos políticos que emergieron en la región desde principios de este siglo?, ¿hacia qué tipo de izquierda viraron?, ¿a qué se denomina izquierda en los tiempos contemporáneos? Estos interrogantes colocaron a las ciencias sociales frente a nuevos desafíos conceptuales, teóricos, cognoscitivos, metodológicos y políticos. Para varios autores, el giro a la izquierda constituyó un fenómeno inesperado (Castañeda, 2006; Luna y Filgueira, 2009; 
Weyland, 2009), considerando especialmente la hegemonía que había logrado el modelo neoliberal en la región, el debilitamiento que las izquierdas ya habían comenzado a sufrir desde la década del ochenta y la presencia de un electorado que se autoidentificaba más con la derecha que con la izquierda (Panizza, 2009). Para otros, las victorias electorales de Chávez en Venezuela en 1999 y de Lula da Silva en Brasil en 2002 ya habrían anticipado la transformación del mapa político latinoamericano a cargo de las izquierdas (Paramio, 2003). Lo cierto es que, habiendo llegado al poder gubernamental a nivel nacional, obteniendo espacios legislativos o empoderándose a nivel de la sociedad civil (Rodríguez Garavito et al., 2008), las izquierdas volvieron a cobrar cierto protagonismo social y político.

En esta dirección surgieron diversos enfoques aunque apoyados en un consenso relativamente sustancial en torno a la distinción entre izquierda y derecha para clasificar a los gobiernos, movimientos y fuerzas políticas. Dicha diferenciación remite a la clásica distinción propuesta por Norberto Bobbio (1997) según la cual las izquierdas abogarían por la igualdad y la transformación del mundo en la perspectiva de volverlo más igualitario, mientras que las derechas lo harían por la libertad sobre la base de que las desigualdades sociales son intrínsecas y necesarias al ordenamiento social. Si bien las “ideas regulativas” que habían orientado el terreno de acción de las izquierdas se modificaron (Arditi, 2009), la apelación a la derecha o izquierda no pierde validez teórica ni práctica (Lievesley y Ludlam, 2009). No obstante es necesario, tal como advierten autores como Vilas (2006) y Panizza (2009), definir a los gobiernos a partir de los contextos específicos y prácticas y agendas políticas que le dan sentido, y no a partir de valores ahistóricos que esencializan los proyectos políticos descontextualizados de su realidad inmediata. Asimismo, autores “postcoloniales” sostienen la necesidad de ir más allá de las etiquetas impuestas por la modernidad eurocéntrica, y comenzar a hablar, además de derecha e izquierda, de "decolonial” dado que muchos de los proyectos progresistas se anclan en un horizonte de crítica a la modernidad colonial (Escobar, 2010; Mignolo, 2006).

En el marco de este consenso, diversos autores han concentrado sus esfuerzos en analizar los procesos políticos contemporáneos a partir de la discusión en torno a las izquierdas en América Latina, especialmente identificando las similitudes y diferencias con aquellas de las décadas anteriores. Mientras algunos académicos retomaron el postulado binario que se apoya en la tesis de las dos izquierdas para sostenerlo y reforzarlo, otros lo criticaron fervientemente por la miopía teórica y empírica que implicaba para el estudio riguroso del fenómeno, debido, en parte, a los criterios normativistas sobre los que se fundamentaba. Entre los primeros, surgieron otro conjunto de caracterizaciones dicotómicas para dar cuenta de los principales rasgos de los "nuevos gobiernos” y de esta forma, diferenciarlos: gobiernos "socialdemócratas" frente a "(neo)populistas o radicales" (Alcántara, 2008; Lanzaro, 2007; Panizza, 2008, Touraine, 2006) , “racionales-gradualistas” versus “populistas-rupturistas” (Moreira et al, 2008), o “responsables” frente a "populistas económicos”( Weyland, 2009). Estas 
tipologías se cimentaron en criterios diversos, desde aquellos asociados a variables institucionales, como la estabilidad y fortaleza del sistema de partidos, hasta variables económicas, como el modo de utilización de los recursos estratégicos, pasando por variables de tipo políticas, como las lógicas de representación predominantes.

Otros estudiosos del tema cuestionaron o matizaron la tesis propuesta por Castañeda -y las tipologías derivadas- al sostener que el campo progresista latinoamericano se caracteriza por una heterogeneidad y diversidad insoslayables (Arditi, 2009; French, 2009; Garretón, 2006; Grugel, 2009; Lievesley y Ludlam, 2009; Ramírez Gallegos, 2006). Esta clasificación invisibilizaría la pluralidad de expresiones políticas que conviven en la región y la convergencia en cada experiencia de rasgos que obedecen a diversas matrices político-ideológicas. Una multiplicidad de aspectos, acuerdan diversos autores, deben considerarse para evitar las simplificaciones al momento de estudiar estos procesos políticos (Beasley-Murray et al., 2010; Roberts, 2007): las trayectorias político-partidarias de los sistemas políticos de cada sociedad, las bases sociales de apoyo, las lógicas de representación política, la composición de las alianzas y los bloques de poder, los perfiles de los liderazgos presidentes, las agendas programáticas (modelo de desarrollo, rol del Estado y postura frente a la globalización, Paramio, 2008), entre otros ${ }^{5}$. Estas dimensiones otorgan a los vigentes procesos políticos especificidades que impiden aglutinarlos de modo uniforme bajo dos etiquetas cerradas lo que, al mismo tiempo, no imposibilita identificar la convergencia de todos ellos en una tendencia regional y horizonte en común (Cleary, 2006; French, 2009; Ramírez Gallegos, 2006). Fundamentalmente, tres son las dimensiones que los vuelven parte de un ciclo político común y diferencia de las "viejas izquierdas": su vínculo con la democracia en tanto régimen político, los contextos de emergencia caracterizados por las herencias neoliberales y el contenido de los proyectos políticos postconsenso de Washington.

En primer lugar, a diferencia del modus operandi de las izquierdas de las décadas del sesenta y setenta, para las "nuevas" izquierdas el sufragio es concebido como el mecanismo -condición necesaria, más no suficientepara lograr acceder a cargos políticos -tanto ejecutivos como legislativosy de esa forma, llevar adelante una agenda de transformación (Arditi, 2009; Garretón, 2006; Vilas, 2010) ${ }^{6}$. La implosión de las dictaduras militares, y luego la definitiva instalación de la agenda neoliberal en América Latina, constituyeron el corolario de la derrota de las fuerzas progresistas latinoamericanas, lo cual condujo a un "cambio cognitivo" en el campo de las izquierdas (Arditi, 2009). Este cambio implicó una modificación tanto en la identificación de los adversarios políticos (los militares y los golpes de Estado pasaron a ocupar ese lugar) como en las estrategias de construcción política (necesidad de procesos electorales y ampliación de los apoyos, más allá de los sectores populares). El proceso de democratización fundamentalmente política- emprendido luego de los gobiernos autoritarios en varios países instaló en el imaginario social, sentido común y praxis política de diversos actores la convicción de que ganar elecciones popula- 
res y convertirse en gobierno constituían la vía disponible más adecuada en detrimento de la vía armada- para lograr transformaciones políticas y profundizar la democracia ${ }^{7}$. A esto se sumó los efectos performativos que tuvo el ethos democrático post-transición al generar las condiciones para que los golpes de Estado (al menos los clásicos) fueran ya ineficaces políticamente. En este sentido, las amplias victorias electorales que lograron los "nuevos" gobiernos los colocaron, a priori, en mejores posiciones, a diferencia de los gobiernos de izquierda de las décadas del sesenta y setenta, para emprender cambios radicales (Ellner, 2012). Incluso, ya una vez instaladas en el poder político, las fuerzas políticas apelaron a sucesivos mecanismos electorales contemplados en las Constituciones para adoptar decisiones políticas. Los diversos referéndums y consultas populares lanzados por los gobiernos de Hugo Chávez en Venezuela, Evo Morales en Bolivia y de Rafael Correa en Ecuador para someter a votación de la sociedad temas relacionados con la reforma constitucional y problemáticas públicas como la seguridad y el papel de los medios de comunicación así lo evidencian, al punto de que se ha hablado a propósito del gobierno correísta como uno en “campaña permanente” (De la Torre, 2013).

En este sentido, la democracia representativa dejó de ser para la izquierda un mero instrumento de las clases dominantes y cobró vigencia como vía de acceso al poder y la transformación social, aunque reconociendo tanto discursiva como prácticamente que la democracia y la política no se agotan en su componente liberal. A contramano de las viejas izquierdas que desconfiaban del elemento liberal de la democracia -participación ciudadana meramente electoral-, las nuevas izquierdas adhieren a él pero lo complementan con otros formatos de intercambio, participación y movilización políticos (Cleary, 2006). En este sentido, hoy las izquierdas latinoamericanas son más postliberales que antiliberales (Arditi, 2009) en la medida que promueven la ampliación de los espacios de participación ciudadana en miras a responder a la demanda de empoderamiento social -voz y capacidad de decisión- de diversos sujetos y colectivos. Asimismo, algunos gobiernos expanden el campo democrático al ampliar los espacios de la política e incorporar otros formatos de la democracia, como la participativa, deliberativa, radical, comunitaria, que se traducen normativamente en las nuevas Cartas Magnas en países como Bolivia, Ecuador y Venezuela (Ellner, 2012).

Esta configuración híbrida así como el amplio apoyo popular a estos gobiernos ha sido interpretado por varios analistas e intelectuales como el resultado del componente carismático que anida en los liderazgos presidenciales de varios de los “nuevos" gobiernos. Estos constituyen una amenaza al régimen democrático (liberal) por sus potenciales derivas autoritarias y populistas, tal como deja entrever la tesis de las “dos izquierdas” propuesta por Castañeda. Al definir a las izquierdas sólo según su compromiso con la democracia - entendida y reducida a su sentido minimalistaCastañeda caracteriza como "buena” a la izquierda moderada que opera en el marco de las instituciones democráticas liberales -ya sea partidos políticos, mercados, organismos financieros internacionales-. Por el contrario, la 
izquierda radical que desafía los cánones liberales a los fines, según su argumento, de concentrar poder político para gobernar, es autoritaria, demagógica y populista, por ende, es la "mala" izquierda. En efecto, esta última caracterización no haría sino volver al populismo una categoría residual desde el momento en que es utilizado más como un descalificativo que como un concepto analítico para dar cuenta de la politicidad de los procesos sociales (Roberts, 2007).

En relación a la segunda dimensión, el contexto social, económico y político en que emergieron los gobiernos de izquierda es completamente diferente al que primaba en décadas previas. Éste se caracteriza, especialmente, por tres rasgos: el profundo empobrecimiento de las sociedades debido a la implementación de las políticas pro-mercado, la creciente movilización política de diversos sectores y actores sociales y la crisis de representación política. Durante las décadas del ochenta y noventa, el arribo del modelo neoliberal en la mayoría de países latinoamericanos provocó procesos de desproletarización lo cual debilitó el poder social de los trabajadores. Hacia 1999, el 9\% de la población latinoamericana estaba desempleada y el $43 \%$ se ubicaba debajo de la línea de pobreza ${ }^{8}$. La estructura socioeconómica de las sociedades se modificó drásticamente: el grueso de trabajadores formales se redujo, las “clásicas” identidades sociales y políticas ancladas en el mundo del trabajo operaron una reconfiguración y nuevos sujetos sociales emergieron -los excluidos del sistema- con novedosas demandas sociales (Moreira et al, 2008).

Las nuevas formas de politización y la ampliación de las esferas públicas a través del surgimiento de poderosos movimientos sociales -indígena, campesinos, derechos humanos, minorías sexuales- actuaron como verdaderos baluartes de resistencia al neoliberalismo (De Sousa Santos, 2001; Ramírez Gallegos, 2006; Svampa, 2005; Van Cott, 2005). A sus luchas se plegaron las de otros colectivos de ciudadanos de clases mediasurbanas, como trabajadores informales y "ahorristas" (las cuales se expresaron en Argentina y Ecuador a través del "Que se vayan todos”) y las de los actores organizados, aunque debilitados, como los sindicatos que decantaron en diversas caídas presidenciales (Argentina en 2001; Bolivia en 2003; Ecuador en 1997, 2000 y 2005) y quiebres de regímenes políticos. Esta crisis de representación política a la que asistieron los países latinoamericanos hacia fines del siglo pasado y principios de este reflejó el fracaso de sus elites políticas para traducir en políticas las aspiraciones de las mayorías (Rodríguez Garavito et. al, 2009).

En definitiva, existe un amplio consenso que identifica la aceleración de las desigualdades sociales, (Ramírez Gallegos, 2006), la "gran asimetría de fuerzas” (Svampa, 2006) y la concomitante movilización política (Cleary, 2006) como los factores gravitantes que generaron las condiciones de posibilidad para el surgimiento de coaliciones políticas y la renovación de partidos con una clara orientación progresista (Lievesly y Ludlam, 2009; Rodríguez Garavito et al., 2009). En efecto, "el ciclo de victorias electorales de la izquierda comienza con la llamada 'media década perdida' (entre los 
años 1998 y 2003), con lo cual puede argumentarse que más que votar por programas de izquierda el electorado votó por cambios de Gobierno" (Panizza, 2009: 79)9 . En este sentido, la victoria electoral de la izquierda responde más a las posturas antipartidocracias que ofrecen los nuevos líderes que a sus posiciones ideológicas (íbid, 2009). No es casual que en las ofertas de campañas electorales y discursos de varios candidatos, luego electos como Presidentes, los organismos internacionales de crédito y las elites políticas tradicionales se hayan establecido como los adversarios políticos por excelencia ${ }^{10}$.

Asimismo, la capacidad creciente de los movimientos y organizaciones sociales para influir en el seno del sistema político -ya sea apoyando o formando parte de los gobiernos- fue un rasgo que caracterizó -aunque de modos diversos- a todos las fuerzas de izquierda gobernante, frente a la centralización alrededor del partido político que definía a la "vieja” izquierda. Bolivia es el ejemplo paradigmático de confluencia entre fuerzas político-partidarias y movimientos sociales que, lejos de resistirse a formar parte de coaliciones gubernamentales, aspiraron a ocupar el gobierno, realizar una reforma democrática del Estado y construir una "hegemonía indígenapopular" (Stefanoni, 2006). No obstante, la relación que entablaron las diversas formas de acción colectiva -especialmente los movimientos sociales- con los gobiernos progresistas y los partidos políticos o coaliciones que los sostienen ha evidenciado una multiplicidad de tensiones a medida que avanzaban los procesos de cambio político.

Por último, la literatura al respecto coincide en que las agendas político-programáticas que construyeron los nuevos gobiernos dan cuenta de una mutación radical de las ideas y valores que habían movilizado a las izquierdas del siglo pasado (Arditi, 2009). Si bien para éstas la política fue considerada también una herramienta de transformación social, los nuevos gobiernos se vieron ante el desafío de recuperarla del vacío y deslegitimidad en los que había caído durante la etapa neoliberal y adecuarla a los nuevos contextos. Asimismo, la revalorización práctica y discursiva del Estado como agente por excelencia de la coordinación social (Lechner, 1997) y como arena privilegiada de interlocución, conflicto y negociación denotan una diferencia respecto a las décadas pasadas durante las cuales la estatalidad era vista por las izquierdas como un instrumento de las clases dominantes que debía ser desmontado (Moreira et al, 2008). A partir de la política y el Estado como palancas del cambio político, los nuevos gobiernos se apoyaron en bloque en un "consenso post-Consenso de Washington" basado en el rechazo al núcleo duro del neoliberalismo (Ramírez Gallegos, 2012a; Thwaites Rey, 2009) y por ende, en la necesidad de desandar el camino construido por el neoconservadurismo político y económico en América Latina desde mediados de la década del setenta en adelante.

De todos modos, las nuevas izquierdas son más moderadas y pragmáticas que sus antecesoras por diversos motivos relacionados, especialmente, a las herencias neoliberales sobre las que deben operar, de ahí el calificativo de "marea rosa" que circuló por diversos medios de comunica- 
ción a partir de la victoria electoral de Tabaré Vázquez en Uruguay. Por ejemplo, el peso de las deudas externas en países como Argentina, Brasil y Ecuador y las estructuras rentistas, como el caso sintomático de Venezuela. Las estructuras jurídicas y financieras supranacionales y la necesaria inserción de los países latinoamericanos en el circuito financiero internacional y los mercados, funcionan como condiciones reales que limitan y constriñen las capacidades de los Estados los cuales se ven impelidos a jugar con esas reglas para sostener los procesos de desarrollo económico (Cleary, 2006 ; Stokes, 2009; Vilas, 2006; Wylde, 2011b). Nadie mejor que Evo Morales lo pudo haber expresado: “El palacio presidencial está lleno de candados. Me siento como un prisionero de las leyes neoliberales" ${ }^{11}$. Por lo tanto, a diferencia de las décadas pasadas, las nuevas izquierdas, incluso las que son consideradas como "radicales", cuestionan más al capitalismo en su fase neoliberal que al sistema capitalista per se, al igual que lo hacen con los principios democráticos al aceptar la democracia representativa pero advirtiendo la necesidad de perfeccionarla y combinarla con otros formatos (Beasley-Murray et al., 2010).

Otros enfoques, por el contrario, en lugar de resaltar los condicionamientos a los que se ven enfrentados las "nuevas izquierdas", enfatizan el contexto económico, político e internacional favorable en que asumieron los gobiernos que les habilitan mayores márgenes de maniobra respecto a décadas pasadas para implementar proyectos radicales (BeasleyMurray et al., 2010). El boom económico de los commodities, la desacreditación de los adversarios ideológicos, el panorama geopolítico caracterizado por la retirada de Estados Unidos del "patio trasero", sumado a la legitimidad electoral ya mencionada, operan como condiciones que habilitan la hegemonía de la izquierda en el poder político. A continuación, se indagará más en profundidad en los contenidos de las agendas programáticas y el papel del Estado en ellas.

\section{Las querellas en torno al post-neoliberalismo y el retorno estatal}

Nombrar la realidad siempre ha constituido objeto de disputas y querellas -semánticas y políticas- en el marco de las ciencias sociales. La emergencia de las experiencias gubernamentales que imprimieron un giro a la izquierda en la región no es la excepción. La proliferación de diversos nombres y calificativos para denotar y explicar el fenómeno ha sido la marca constitutiva de las discusiones al respecto. Gobiernos “postneoliberales”, “progresistas”, “neodesarrollistas”, “populistas” o "socialismo del siglo XXI", han sido los diversos calificativos con los que se procuró nombrar a las nuevas experiencias políticas. Particularmente, se prestó atención a las continuidades y rupturas que implicaron con el modelo neoliberal -incluso con el sistema capitalista como taldado que, tal como se desarrolló en la sección anterior, los nuevos gobiernos surgieron en gran medida a raíz del resultado de las consecuen- 
cias negativas que significaron las políticas pro-mercado para gran parte de las sociedades latinoamericanas.

Quizá fue la noción de postneoliberalismo la que mayor impacto y controversias haya suscitado como categoría para dar cuenta de ese tan pregonado “cambio de época” (Svampa, 2008). Su emergencia se respondió a la necesidad de evidenciar no sólo un cambio cronológico sino también el comienzo de una etapa cualitativamente diferente respecto al contenido de las agendas políticas y económicas. Varios cientistas sociales acuerdan que la noción de postneoliberalismo, en detrimento de otras, informa acerca del compromiso de los proyectos políticos de los nuevos gobiernos para superar el núcleo duro del programa impuesto por los organismos internacionales de crédito bajo el nombre de “Consenso de Washington” (French, 2009; MacDonald y Ruckert, 2009; Ramírez Gallegos, 2012a; Sader, 2008). Al mismo tiempo, si bien denota un ideal regulativo de superación, el neologismo convoca a pensar en las continuidades con el modelo neoliberal dado los escenarios económicos y políticos en los que se desenvuelven los gobiernos progresistas (Ramírez Gallegos, 2007).

Para algunos, la categoría alude a dos cuestiones articuladas: a un tipo de modelo de desarrollo que aspira a lograr crecimiento económico y redistribución social a favor de los más desfavorecidos y a una matriz de inclusión socio-política que combina diversos formatos democráticos (Grugel y Riggirozzi, 2012; Wylde, 2011b). Así como el neoliberalismo no fue sólo un paradigma económico, sino un modelo orientado a reconfigurar las subjetividades sociopolíticas, a operar como representación del mundo y en definitiva, a configurar el ordenamiento social, la idea de postneoliberalismo apunta, necesariamente, a un modo particular de construcción de la totalidad social, no a una mera dimensión económica.

Otros autores asocian al postneoliberalismo especialmente con problemáticas relacionadas al modelo económico y la política exterior. Políticas opuestas a la desregulación, la financiarización, la flexibilidad del trabajo y al libre mercado constituyen la base de cualquier proyecto postneoliberal (Sader, 2008). Asimismo, la búsqueda de una construcción de bloques regionales en los cuales insertarse no sólo comercial sino también políticamente de modo de quebrar la integración global que el (neo)liberalismo promovió (Ramírez Gallegos, 2012a), constituye un elemento insoslayable del horizonte postneoliberal. Las nuevas estrategias geopolíticas que activaron los gobiernos de izquierda a través de estructuras regionales como la Unión de Naciones Suramericanas (UNASUR), la Comunidad de Estados Latinoamericanos y Caribeños (CELAC), el Banco del Sur, la Alianza Bolivariana para los Pueblos de Nuestra América (ALBA), Petrocaribe, dan cuenta de un "nuevo continentalismo" (Ceceña, 2011; Lievesley, 2009). No obstante, según algunos autores, la vieja consigna “antiimperialismo” ya no se traduce en un rechazo categórico al capitalismo y sus lógicas sino a la necesidad de conformar y reconfigurar los bloques regionales para potenciar la soberanía nacional de cada país en el marco de un sistema de tipo capitalista (Garretón, 2006). 
Para otros autores, en cambio, la noción reviste un débil potencial heurístico y explicativo, “con poca vida propia” (Ceceña, 2011: 123), en la medida en que el prefijo "post" es poco específico y abre un campo indefinido de alternativas en relación a las vías escogidas por los gobiernos para lograr una transformación. Nada informa acerca del contenido y orientaciones por las cuales han apostado los nuevos gobiernos en vistas a superar el ordenamiento neoliberal (Rovira Kaltwasser, 2011). En ese sentido, se establece como un concepto que carece de apelativo propio y es definido por la negatividad o superación, más que por su positividad (Ceceña, 2011: 123). Asimismo, deja por fuera a aquellas fuerzas sociales que, sin llegar a constituirse en gobierno, optaron una salida al neoliberalismo por fuera de los canales electorales y la "institucionalidad dominante" (íbid: 130). La construcción de espacios comunitarios bajo el principio de autodeterminación y autosustentación, incluso con anterioridad a la implantación de la hegemonía neoliberal, no podría, entonces, ser recuperado en el campo semántico en que abreva el postneoliberalismo. Por último, algunos cientistas sociales sostienen que la categoría podría invisibilizar las continuidades que caracterizan a los proyectos políticos de los gobiernos progresistas con el modelo neoliberal. Tal como sostiene Svampa, "hablar de la crisis del consenso neoliberal no significa en absoluto afirmar que hemos entrado en la etapa del posneoliberalismo o que hemos instalado ya una agenda posneoliberal” (2006: 147).

A pesar de estas discrepancias acerca del contenido de la categoría así como su utilidad para el análisis político, todos los enfoques acuerdan que es una noción que involucra necesariamente la dimensión estatal. Los gobiernos de izquierda o centro-izquierda, en mayor o menor medida, colocaron al Estado en el centro neurálgico del ordenamiento social e intentaron dotarlo de las funciones que por definición cumple: regulación, representación y conducción política (Lechner, 1997). Gran parte de la literatura acuerda en que la recuperación de las capacidades estatales, otrora opacadas y minimizadas, constituye uno de los elementos en el que todos estos gobiernos se fundaron y legitimaron para llevar adelante las agendas de cambio político e invertir la relación entre política y economía a favor de la primera ${ }^{12}$ (Ramírez Gallegos, 2010; Vilas, 2010). El Estado se posicionó en estas experiencias políticas como agente de coordinación social y al mismo tiempo como el encarnador de un nuevo pacto social (Garretón, 2006; Grugel y Riggirozzi; 2012; Thwaites Rey, 2010; Wylde, 2011a). En este sentido, la centralidad del Estado en la determinación de la agenda pública, la redistribución de la riqueza y la inclusión social ha sido un factor clave en la disputa política abierta durante estos gobiernos.

Un aspecto asociado al "retorno del Estado" que fue retomado por la bibliografía especializada fue su "autonomía relativa” para desplegar sus funciones (Garretón, 2006; Grugel y Riggirozzi, 2009; Ramírez Gallegos, 2012b; Tapia, 2009). La ampliación del margen de autonomía estatal respecto a los “conjuntos económico-sociales de la sociedad civil así como de las fracciones o clases dominantes” (Poulantzas, 1976: 120), es decir, el poder global, los grupos de intereses y poderes fácticos de diverso signo afines al man- 
tenimiento de la agenda neoliberal ha sido una preocupación constante por parte de las fuerzas gobernantes. El Estado se volcó hacia un proyecto político de tipo nacional a través del fortalecimiento de los factores internos de producción, el control de los mercados y capitales y el aumento de los márgenes de participación estatal -en detrimento de los capitales concentrados transnacionales y locales- en los ingresos generados, para de esa forma redistribuirlos hacia los sectores más desfavorecidos (Ceceña, 2012; Ramírez Gallegos, 2012b; Thwaites Rey, 2010) ${ }^{13}$.

Para lograr ampliar los márgenes de autonomía estatal, algunos países reconfiguraron la arquitectura institucional del Estado en vistas a recuperar la rectoría de las políticas públicas en diferentes áreas. Esto tuvo efectos sobre los patrones de relacionamiento entre la acción pública y los diversos actores sociales, tanto asociados a los grupos empresarios y financieros como a los movimientos sociales. En efecto, gran parte de la conflictividad política desplegada en los países se debió a la decisión gubernamental de poner coto a la captura de las instituciones estatales y diversos recursos por parte de intereses particulares. El conflicto constituyó un eje transversal a los procesos políticos del "giro a la izquierda", el cual "condicionó el tiempo político de los nuevos gobiernos y abrió un momento fundamentalmente antagónico en la política democrática de la región” (Ramírez Gallegos, 2010b: 134). Este momento antagónico involucró un heterogéneo conjunto de actores socio-políticos: algunos se mostraron renuentes a aceptar los contenidos de las políticas orientadas a modificar el status quo, otros rechazaron de plano un cambio en la correlación de fuerzas políticas y en su capacidad -poderosa durante el neoliberalismo- de intervenir en el seno del Estado, y asimismo, actores que se resistieron a las formas de hacer política de estas experiencias gubernamentales.

Por lo tanto, evocar la idea de postneoliberalismo sin referirse al contenido y orientación que asumen los Estados latinoamericanos es problemático (Wylde, 2011a) en la medida en que la estatalidad se constituye en un eje fundamental de los actuales procesos. No obstante, el postneoliberalismo alude a algo más que al "retorno del Estado" ya que sugiere nuevos sentidos atribuidos al Estado y a lo político (Almeida y Johnston, 2006; Grugel y Riggirozzi, 2012). De esta forma, pareciera que la noción de postneolibralismo aporta más para comprender la centralidad y contenidos que adquiere el Estado que el grado en el cual las agendas políticas logran revertir las políticas neoliberales y sus efectos.

Para superar las limitaciones señaladas de la noción de postneoliberalismo, varios autores avanzaron en análisis más específicos sobre las vías y estrategias de cambio que adoptaron los diversos gobiernos. Gran parte de la literatura acuerda en que existen principalmente dos grandes "trayectorias de gestión política del cambio" pese a compartir el énfasis en la reconstrucción de las capacidades estatales como estrategia principal (Ramírez Gallegos, 2013). Por un lado, algunos países optaron por una "ruptura radical” (íbid, 2013) o una "refundación” (Sader, 2008; De la Torre, 2013) del ordenamiento político (tanto del régimen político como de la 
forma-Estado), como los casos de Bolivia, Ecuador y Venezuela. No es casual, en este sentido, que en estos países los procesos políticos hayan sido denominados como "revoluciones" (Revolución Democrática y Cultural, Revolución Ciudadana y Revolución Bolivariana, respectivamente). Por otro lado, algunos países optaron por una estrategia reformista de cambios graduales en el marco del sistema y régimen político vigentes, como los casos de Brasil, Uruguay y Argentina. Si bien esta caracterización al parecer coincide con la tesis de las “dos izquierdas”, a continuación se verá que los casos combinan elementos de distintas estrategias de cambio.

La estrategia “refundacional” consiste en la implementación de cambios contundentes y radicales tendientes no sólo a superar las crisis sociales y económicas sino especialmente a erigir una nueva comunidad política (Ramírez Gallegos, 2013). Esta vía del cambio no apuesta a superar el modo de acumulación capitalista (al menos, no en el corto plazo) pero no desestima en avanzar, aun tímidamente, con decisiones y políticas "postcapitalistas" (Sader, 2008) en la perspectiva de favorecer a las grandes mayorías. Por ejemplo, tanto en Bolivia como en Ecuador los gobiernos han renegociado los contratos con empresas petroleras internacionales así como han nacionalizado otras en pos de que el Estado intercepte mayor renta. Incluso en Ecuador, una de las primeras decisiones políticas adoptada por el presidente Correa fue dejar sin caducidad el contrato con la petrolera norteamericana OXY. Asimismo, tanto en Venezuela como en Ecuador algunas empresas fueron expropiadas (en Venezuela empresas vinculadas al petróleo y alimentos, como “Alimentos Polar” y "Cargill” -ver López Maya y Lander, 2010-; en Ecuador vinculadas a los medios de comunicación, como las del Grupo Isaías ${ }^{14}$ y agro, como La Clementina ${ }^{15}$ ).

Esta vía combina tres estrategias: por un lado, apela a la vocación transformacional de los liderazgos presidenciales; por otro, convoca a continuas contiendas electorales para aceitar la participación ciudadana que refuerce la legitimidad gubernamental; y por último, procura la reconfiguración de la estatalidad -tanto su morfología como funcionamiento- a través de reemplazos constitucionales. Esto en el marco de un estilo de gestión política de tipo decisionista que no es privativo de los gobiernos de los países andinos sino que también marca los procesos políticos de países como Argentina, Brasil y Uruguay. Incluso el carácter decisionista y presidencialista no es una novedad sino que constituye un rasgo inherente a los regímenes políticos de gran parte de los países (plasmados en las Constituciones previas, Negretto 2009) y que en las actuales experiencias políticas se reactualiza. Este tema ha sido ampliamente abordado por la literatura (gran parte de ella, desde la perspectiva del populismo) identificando dos aspectos (Novaro, 2011; Ramírez Gallegos, 2010b; Reinoso, 2008). Por un lado, esta forma de gestionar la agenda pública desestima los procesos deliberativos por considerarlos retardatarios para la toma de decisiones rápidas y eficientes en un momento político que exige una alta ejecutividad, tanto para emprender las reformas constitucionales como para avanzar en el quiebre de la agenda neoliberal. Por otro lado, al centralizarse los mecanismos en la figura del Presidente, se fortalece su soberanía en la medida en 
que las decisiones políticas adoptadas ponen de manifiesto su capacidad política para lograr márgenes de autonomía y poder decisional respecto a los actores sociales y políticos del sistema político (Poder Legislativo, Poder Judicial, partidos políticos) y la sociedad civil (organizaciones y movimientos sociales, poderes fácticos como corporaciones). No obstante, hay coyunturas en que este carácter decisionista no prescinde de otros modos de construcción política, como es la participación ciudadana.

En efecto, en los países andinos como Bolivia, Ecuador y Venezuela, el carácter decisionista se puso de manifiesto en los procesos de reformas constitucionales que se establecieron como los mecanismos fundamentales para el cambio como resultado de las demandas represadas por diversos actores sociales. Varios autores han hablado de un "nuevo constitucionalismo latinoamericano” para referirse al recambio constitucional impulsado “desde abajo” como palanca de transformaciones sustanciales del ordenamiento social y solución al problema de la desigualdad social (Gargarella y Courtis, 2009; Lalander, 2011; Viciano y Martínez, 2011). Las demandas por recambios constitucionales se iniciaron en Bolivia a principios del siglo con la Marcha de los Pueblos Indígenas y Originarios; en Ecuador de la mano del movimiento indígena en el marco de la reforma constitucional de 1998 la cual si bien reconocía derechos sociales de un amplio espectro de actores sociales, garantizaba la continuidad del modelo neoliberal.

Esta perspectiva asume que la Constitución es un mandato directo del poder constituyente -el pueblo- y por lo tanto único fundamento del poder constituido. La legitimidad de la Constitución puede ser solo extrajurídica, por lo tanto, la instalación de una Asamblea Constituyente democrática se vuelve imperiosa en cada uno de estos procesos políticos. En efecto, en los tres países andinos la convocatoria y posterior desarrollo de Asambleas Nacionales Constituyentes fue el mecanismo que habilitó la implementación de las agendas políticas de cambio y potenció la legitimidad de los procesos políticos. Asimismo, este enfoque combina elementos de la democracia liberal con la radical al profundizar la concentración de poder en el Ejecutivo y al mismo tiempo ampliar la participación ciudadana a través de diversos mecanismos (Lalander, 2011).

Los avances que han implicado los procesos de cambio constitucional en términos de derechos sociales, empoderamiento de sectores sociales y participación política no han evitado la activación de conflictos políticos provenientes de diversos sectores. Al haber incluido en las nuevas Constituciones directivas económicas y políticas que trastocan estructuras de poder arraigadas y apuntalan el rol del Estado en la economía (Gargarella y Courtis, 2009), la emergencia de una multiplicidad de disputas y enfrentamientos políticos fue sintomática. En efecto, en los países andinos estos procesos han estado atravesados por turbulentos escenarios de polarización que han llegado al punto de configurarse en golpes de Estado (Venezuela), en confrontación regional entre poderes locales (Bolivia) o en pugna institucional exacerbada que decantó incluso en la caída del parla- 
mento nacional (Ecuador), por mencionar algunas de las derivas del conflicto en tales países ${ }^{16}$.

Incluso, varias de esas tensiones provienen de las propias contradicciones de los cuerpos constitucionales. Por ejemplo, en las Constituciones de Bolivia y Ecuador, la incorporación del paradigma del "buen vivir" reconocimiento de los derechos de la naturaleza; autonomías indígenas; límites a la actividad extractiva- se ha perfilado como un componente fundamental de una agenda encaminada a implementar alternativas al desarrollo capitalista (Escobar, 2010). No obstante, esta agenda choca con diversos principios rectores contenidos en las Constituciones. La centralidad otorgada al Estado en el marco de la construcción de un proyecto que abreva en una matriz nacional-popular (Stefanoni, 2006; 2012) entra en tensión con el componente plurinacional atribuido al Estado así como con las autonomías indígenas reconocidas. Asimismo, parece existir cierta incompatibilidad entre el relanzamiento de un Estado orientado a ampliar y garantizar derechos -para lo cual requiere afianzar sus capacidades de acumulación para luego redistribuir-, y las fuertes regulaciones para el uso y explotación de los recursos naturales que constituyen el motor de esas economías. El presidente Correa lo puso de manifiesto al afirmar provocativamente que "no podemos vivir como mendigos sentados sobre un saco de oro"17. Tanto en los países andinos como en los países del Cono Sur cuyos modelos de desarrollo se asientan en la explotación de los recursos naturales y la inserción global de las naciones como proveedoras de materias primas, las luchas socio-ambientales se han catapultado como una de las conflictividades más estridentes, aunque con una, por ahora, aparente debilidad para proyectarse más allá de la experiencias locales. En este sentido, los debates entre "extractivistas" y "ambientalistas" han sido sintomáticos de este relativamente novedoso campo de conflictividad ${ }^{18}$ que es compartido tanto por los países que escogieron la vía refundacional o "gradualista”.

La elección de la estrategia "refundacional” ha sido explicada desde diversas perspectivas. Algunas privilegian la dimensión institucional al sostener que la nula o débil institucionalización de los sistemas de partidos constituye una variable que habilita condiciones para la emergencia de nuevas coaliciones o movimientos políticos. De esta forma, la crisis de representación de fines del siglo pasado y principios de éste habría generado las oportunidades para que nuevas clases políticas capitalizaran el malestar y las luchas en resistencia al neoliberalismo. El Movimiento al Socialismo en Bolivia, Alianza País en Ecuador y el Partido Socialista Unido de Venezuela dan cuenta de este aspecto. Para otros enfoques, la elección de la "ruptura radical" reside en un factor de orden estrictamente económico: la bonanza económica internacional (aumento mundial de la demanda de materias primas y de sus precios) permitió a estos gobiernos prescindir de construcción institucional, modelos de desarrollos productivos y procesos de interlocución, compromisos y negociación con diversos intereses (López Maya y Panzarello, 2012; Weyland, 2009; Wylde, 2011a) deviniendo en un “populismo económico o rentista” (Paramio, 2003). 
Respecto a la segunda trayectoria de gestión del cambio político, algunos gobiernos optaron por una vía de cambios graduales a partir de una política económica que combina elementos ortodoxos y heterodoxos. No apelaron a una transformación radical del régimen político y sistema partidario, sino que, operando en ese marco, procuraron llevar adelantes cambios en el plano del desarrollo económico y la justicia distributiva (Ramírez Gallegos, 2013). Las categorías “neodesarrollismo” (Bresser Pereira, 2007; Féliz, 2011; Wylde, 2011a, 2011b) y “neoestructuralismo” (Leiva, 2008) afloraron precisamente para dar cuenta de la estrategia sobre los que estos países se apoyan.

Si bien recupera elementos del desarrollismo de inspiración keynesiana de las décadas del 50 y 60, se aleja de él así como de la ortodoxia neoliberal y del “populismo burocrático izquierdista” (Bresser Pereira, 2007). A grandes rasgos, el nuevo desarrollismo implica dos cuestiones. En primer lugar, el Estado-nación se coloca como eje neurálgico y promotor de una estrategia que impulsa políticas comerciales y productivas, y busca inversión financiera, orientadas al desarrollo capitalista nacional. El Estado se posiciona como un competidor más en el contexto global aunque con una firme postura de rechazar la importación de esquemas o teorías foráneas. En segundo lugar, esta estrategia reconoce la necesidad de insertarse mundialmente en los mercados y operar con el capital transnacional pero con la mira puesta en el crecimiento económico, cohesión social y redistribución del ingreso a nivel nacional. Para ello, se sustenta en un acuerdo nacional que involucra a las diversas fracciones del capital y trabajo. Sin pacto social, no habría estrategia de desarrollo. Estos dos elementos, como se puede observar, también están presentes, aunque de otro modo, en la estrategia refundacional. No obstante, gobiernos como los de Venezuela y Ecuador son menos proclives a construir pactos sociales -muchos de ellos de tipo corporativo- , por ende, emprender procesos de negociación y ceder ante lo que consideran intereses particulares, tanto provenientes de sindicatos de trabajadores como de fracciones capitalistas.

En parte, la elección de la vía más moderada y gradualista reside en que en esos países, como Argentina, Brasil y Uruguay, los sistemas políticos y partidarios son relativamente fuertes e institucionalizados. Los casos del Partido Justicialista en Argentina -palanca para la formación de la alianza Frente para la Victoria que llegó al poder en 2003-, del Partido de los Trabajadores en Brasil -sustrato político-electoral del ascenso de Lula da Silva al gobierno- y del Frente Amplio en Uruguay son ejemplos paradigmáticos.

\section{Consensos y tensiones en los debates sobre giro a la izquierda}

Que la palabra “cambio” atraviesa a los procesos políticos contemporáneos de este siglo no suscita la mínima duda e incluso, parece una verdad de Perogrullo. A pesar de la distancia que existe entre los diversos 
enfoques dedicados a analizar las experiencias políticas del "giro a la izquierda”, todos, en menor o mayor medida, reconocen las transformaciones sociales, políticas, económicas y culturales que se operaron en las diversas naciones latinoamericanas con la emergencia de los gobiernos de izquierda. Asimismo, identifican al neoliberalismo -y su crisis- como una coyuntura crítica, un acontecimiento, que constituyó un punto de inflexión en el devenir de los procesos políticos en la región. Ahora bien, las discrepancias residen en el peso y naturaleza que se otorga a las mismas. En este sentido, el orden de los factores sí altera el producto: mientras que algunos defienden la tesis del "cambio de época", otros apoyan la de la "época de cambios”. Como se observó a lo largo del artículo, algunas perspectivas consideran que efectivamente el surgimiento de las nuevas experiencias políticas implicó una transformación radical no sólo de las estructuras económicas, sino de los paradigmas sobre los que se configuran las sociedades. Para estos enfoques, los casos de Bolivia, Ecuador y Venezuela son los que dieron enormes pasos en este sentido. Otras lecturas del fenómeno son más "cuidadosas" al señalar la radicalidad de las experiencias y se detienen en las continuidades que se identifican con las décadas pasadas. A grandes rasgos, son dos los aspectos que suscitan las mayores controversias: el carácter democrático de los vigentes procesos políticos y la potencialidad que revisten para lograr una real transformación.

Respecto al primero, la cuestión de la democracia es un tema recurrente en los debates sobre la política en América Latina. En el marco de los vigentes procesos políticos, nuevamente emergen las diversas acepciones y enfoques sobre la democracia para caracterizar a los nuevos gobiernos. Desde aquellos que reducen la democracia a sus formas liberales hasta aquellos que adoptan una perspectiva "sustancial” a partir de la cual democracia es necesariamente sinónimo de emancipación social y política sin prestar atención a si obedece a los principios liberales clásicos, como la tan pregonada "libertad negativa". De esta forma perspectivas que atribuyen un alto componente democrático a experiencias como las de Chile por su respeto a las instituciones democráticas -como la separación de los poderes de Estado-, consideran, por el contrario, que países como Venezuela corren el riesgo de desmantelar -si aún no lo han hecho- el régimen democrático. No obstante, aquí comienzan a jugar una serie de factores, como los económicos, sociales y culturales que matizan estas distinciones cerradas. Así, en experiencias como las de Bolivia, Ecuador, Venezuela y Argentina la proliferación de instancias y espacios de participación popular significan un avance democrático teniendo en cuenta que históricamente fueron países con mayorías dominadas por elites económicas y políticas que dirigían los gobiernos de espaldas a la ciudadanía.

En relación al segundo aspecto, las mayores controversias académicas y políticas reposaron en la potencialidad de estos procesos político para lograr una genuina transformación de cara a empoderar a los sectores históricamente perjudicados. De esta forma, la cuestión de los liderazgos presidenciales -la concentración de poder en el Ejecutivo, su carácter decisionista, el problema de la sucesión presidencial-; las condiciones es- 
tructurales que caracterizan a las economías latinoamericanas -primarioexportadoras- y su necesaria inserción en el contexto geopolítico y económico transnacional, los impactos de la globalización de corte aún neoliberal, la tensión entre diversas cosmovisiones de pueblos y nacionalidades con los modelos de (y al) desarrollo, constituyen algunos de los terrenos que continúan -y continuarán- suscitando las mayores polémicas, tanto teóricas y políticas, no exentas, por supuesto, de fuertes supuestos normativos.

En este sentido, uno de los mayores desafíos que actualmente atraviesa la sociología y ciencia políticas latinoamericanas es procurar abriendo la discusión en torno a los procesos socio-políticos prestando atención a las especificidades que caracterizan a la región y dentro de ella, a cada país. Esto implica un ejercicio de creatividad e "imaginación sociológica y política” que evite la importación de esquemas foráneos y ajenos a nuestras realidades. Parafraseando a Boaventura de Sousa Santos, es necesario “conocer desde el Sur” lo que acontece en el sur para de este modo, proponer nuevas formas de pensar las totalidades. 


\section{Notas}

${ }^{1}$ Este trabajo forma parte de la actual investigación que estoy realizando en el marco de la beca doctoral del Consejo Nacional de Investigaciones Científicas y Técnicas (CONICET) en el Instituto de Investigaciones en Humanidades y Ciencias Sociales de la Universidad Nacional de La Plata, Argentina. Agradezco los rigurosos comentarios de Martín Retamozo.

${ }^{2}$ Chávez fue electo en Venezuela en 1998. Luego, se fueron sumando otros partidos o coaliciones progresistas: Lula Da Silva en Brasil en el año 2002; Kirchner y Fernández de Kirchner en 2003 y 2007 respectivamente en Argentina; Vázquez gana las elecciones en Uruguay en 2005; el Partido Socialista en Chile, con Lagos y Bachelet en 2000 y 2005 respectivamente; Morales en Bolivia en el año 2006; Ortega en Nicaragua, Correa en Ecuador y Colom en Guatemala en 2007, Funes en El Salvador y Lugo en Paraguay en el año 2009 (éste no concluyó su mandato).

${ }^{x}$ Con excepción de algunos trabajos que realizan una suerte de estado de la cuestión respecto al "giro a la izquierda", como Alegre, 2008; Lievesley y Ludlam, 2009; Rovira Kaltwasser, 2011; Stokes, 2009. Llama la atención la cantidad de literatura elaborada por autores no latinoamericanos así como publicada en revistas y libros editados en Europa y los Estados Unidos especialmente.

${ }^{4}$ Cabe resaltar que los casos de Bolivia y Venezuela aparecen como los más recurrentes en los trabajos sobre "giro a la izquierda" (Beasley-Murray et. al, 2010).

${ }^{5}$ Por cuestiones de espacio, en este trabajo no se aborda cada una de estas dimensiones. De forma general, se repasan los debates principales que involucran algunos de esos aspectos analíticos, como las agendas programáticas. Además, tal como sostiene Vilas acera de las similitudes que pueden identificarse entre las experiencias políticas, "es el conjunto, más que sus elementos integrantes, el que permite identificar los aspectos novedosos de la escena política regional” (2006: 98).

${ }^{6}$ Con excepción del caso de la Unidad Popular en Chile que optó por la vía electoral en 1970.

${ }^{7}$ Las organizaciones, partidos y movimientos que apelan hoy en día en América Latina a la vía armada son excepcionales (Sendero Luminoso en Perú, las Fuerzas Armadas Revolucionarias Colombianas, el Ejército Popular Revolucionario y el Ejército Zapatista de Liberación Nacional en México).

${ }^{8}$ Datos extraídos de los documentos elaborados y publicados por la CEPAL. http:// www.cepal.org/cgibin/getProd.asp?xml=/publicaciones/xml/4/7924/P7924.xml\&xsl=/ dds/tp1/p9f

${ }^{9}$ Algunos estudios han analizado la relación entre estratos socio-económicos e intención de voto. Ver Moncagatta y Safranoff (2013).

${ }^{\circ 0}$ Ver los trabajos de Retamozo y Muñoz (2009 y 2013) para el caso argentino; De la Torre (2013) y Ramírez Gallegos (2010a) para el caso ecuatoriano; y Quiroga (2010) para el caso boliviano. 
${ }^{11}$ Entrevista realizada a Evo Morales por Paul Mason (Cleary, 2006).

${ }^{12}$ Varios análisis inspirados en los trabajos de K. Polanyi consideran que hablar de "intervención o retirada del Estado" es falaz dado que éste es parte constitutivo de la economía, su presencia es inerradicable. En este sentido, durante la etapa neoliberal el Estado no habría desaparecido, sino que habría intervenido en la dirección de privilegiar al mercado como mecanismo de coordinación social (Clark, 2012).

${ }^{13}$ Para un análisis de la intervención estatal en diversas áreas de política a nivel latinoamericano ver Thwaites Rey, 2012.

${ }^{14} \mathrm{El}$ Grupo Isaías es uno de los conglomerados económicos y mediáticos más poderosos de Ecuador. El Filanbanco, propiedad del Grupo Isaías, había financiado la campaña electoral del candidato Jamil Mahuad y fue uno de los protagonistas de la crisis financiera del año 1999 como producto de lo cual se incautaron los depósitos de los ciudadanos.

${ }^{15}$ En mayo de 2013, se embargó y expropió esta hacienda, propiedad del magnate empresario bananero Álvaro Noboa, debido a la cuantiosa deuda que mantenía con el Estado (95 millones de dólares) para traspasarla a los dos mil trabajadores de dicha unidad productiva.

${ }^{16}$ Sobre el caso boliviano ver De La Fuente Jeria (2008) y Mayorga (2009), sobre Venezuela, López Maya (2003) y sobre el caso ecuatoriano, Machado (2008)

${ }^{17}$ Discurso pronunciado por Rafael Correa el 15 de enero de 2009 ante la Comisión Legislativa durante en el segundo año de gobierno. En http://www.presidencia.gob.ec/ discursos/. Consultado el 15 de agosto de 2014.

18 Ver Gudynas (2009; 2010), Svampa (2009) y revista OSAL (número 32, 2012 


\section{Bibliografía}

Alcántara, Manuel (2008), “La escalada de la izquierda. La ubicación ideológica de presidentes y partidos de izquierda en América Latina”. En Nueva Sociedad, $\mathrm{N}^{\circ} 217$, pp. 72-85.

Alegre, Pablo (2008), “Los 'giros' a la izquierda en el Cono Sur: gobiernos progresistas y alternativas de desarrollo en perspectiva comparada”. Informe final del concurso: Gobiernos progresistas en la era neoliberal: estructuras de poder y concepciones sobre el desarrollo en América Latina y el Caribe. Programa Regional de Becas CLACSO.

Almeida, Paul y Johnston, Hank (2006), Latin American Social Movements: Globalization, Democratization and Transnational Networks. Rowman amd Littlefield, Lanham.

Arditi, Benjamín. (2009), “El giro a la izquierda en América Latina: ¿una política post-liberal? En Ciências Sociais Unisino, 45(3), pp. 232-246.

Beasly-Murray, Jon, Cameron, Maxwell y Hershberg, Eric (2010), “Latin America's left turns: a tour d'horizon”. En Cameron y Hershberg. Latin America's Left Turns: Politics, Policies, and Trajectories of Change. Lynne Rienner Publishers, Boulder.

Bobbio, Norberto (1997), Derecha e izquierda, razones y significados de una distinción política. Gráfica Internacional, España.

Bresser-Pereira, Luiz Carlos (2007), "Estado y mercado en el nuevo desarrollismo”. Revista Nueva Sociedad, N²10, pp. 110-125.

Castañeda, Jorge (2006), “Latin America's Left Turn”. En Foreign Affairs, 85, (3), pp. 28-43.

Ceceña, Ana Esther (2011), "Postneoliberalismo o cambio civilizatorio”, en Dos Santos T. (ed), América Latina y el Caribe: Escenarios posibles y políticas sociales, Proyecto Repensar América Latina, Vol. 3. UNESCO / FLACSO, Montevideo.

Comisión Económica para América Latina y el Caribe, http://www.cepal.org/ cgibin/getProd.asp?xml=/publicaciones/xml/4/7924/P7924.xml\&xsl=/dds/ tp1/p9f. Consultado el 8 de octubre de 2014.

Clark, Timothy David (2012), "Putting the Horse Before the Cart: Neoliberalism and Post-Neoliberalism in Chile”. Paper presented at the Annual Conference of the Canadian Political Science Association (CPSA), University of Alberta.

Cleary, Matthew (2006), “Explaining the left's resurgence”. En Journal of Democracy, pp. 35-49. 
De la Fuente Jeria, José (2008), “Los alrededores de la Asamblea Constituyente”, en Tinkazos, Revista Boliviana de Ciencias Sociales, № 23-24, pp. 85-100.

De la Torre, Carlos (2013), "El tecnopopulismo de Rafael Correa ¿Es compatible el carisma con la tecnocracia?”. En Latin American Research Review, pp. 24-43.

De Sousa Santos, Boaventura (2001), “Los nuevos movimientos sociales”. En OSAL, pp. 177-188.

Ellner, Steve (2012), “The Distinguishing Features of Latin America's New Left in Power: The Chávez, Morales, and Correa Governments”, en Latin America Perspectives, Issue 182, N 1, January, pp. 96-114.

Escobar, Arturo (2010), "Latin America at a crossroads. Alternative modernizations, post-liberalism, or post-development?”. En Cultural Studies, pp. 1-65.

Féliz, Mariano (2011), “Neoliberalismos, neodesarrollismos y proyectos contrahegemónicos en Suramérica”. En Revista Astrolabio, pp. 238-265.

French, John (2009), “Understanding the Politics of Latin America's Plural Lefts (Chavez/Lula): social democracy, populism and convergence on the path to a post-neoliberal world”, en Third World Quarterly, Taylor \& Francis.

Gargarella, Roberto y Courtis, Christian (2009), “El nuevo constitucionalismo latinoamericano: promesas e interrogantes”. En CEPAL, Naciones Unidas, Santiago de Chile.

Garretón, Manuel Antonio (2006), “Modelos y liderazgos en América Latina”, en Nueva Sociedad N²05, pp. 103-113.

Grugel, Jean (2009), “'Basta de realidades, queremos promesas’. Democracy after the Washignton Consensus”. En Grugel y Riggirozzi, Governance after Neoliberalism in Latin America, Palgrave Macmillan, New York.

Grugel, Jean y Riggirozzi, Pía (2009), “The end of the Embrace? Neoliberalism and Alternatives to Neoliberalism in Latin America”. En: Grugel, J. y Riggirozzi, P. (eds), Governance after Neoliberalism in Latin America, Palgrave Macmillan, New York.

Ídem (2012), "Post-neoliberalism in Latin America: Rebuilding and Reclaiming the State after Crisis”, en Development and Change, 43, 1, International Institute of Social Studies, pp. 1-21

Gudynas, Eduardo (2009), “Diez tesis urgentes sobre el Nuevo extractivismo. Contextos y demandas bajo el progresismo sudamericano actual”. En Extractivismo, política y sociedad, CAAP y CLAES, Quito, pp-187-225. 
Gudynas, Eduardo (2010), “Si eres tan progresista ¿Por qué destruyes la naturaleza? Neoextractivismo, izquierda y alternativas”. En Ecuador Debate, pp. 61-81.

Lalander, Rickard (2011), ¿Descentralización socialista? Reflexiones sobre democracia radical, participación política y el neoconstitucionalismo del siglo XXI en Bolivia, Ecuador y Venezuela. En Politeia, pp. 55-88.

Lanzaro, Jorge (2007), “Las izquierdas latinoamericanas: entre el populismo y la socialdemocracia”. En http://www.cecies.org/imagenes/ edicion_116.pdf\#page=20

Lechner, Norbert (1997), “Tres formas de coordinación social”. En: Revista de la CEPAL, $\mathrm{n}^{\circ}$ 61, pp.

Leiva, Fernando Ignacio (2008), “Toward a Critique of Latin American Neostructuralism”. En: Latin American Politics and Society, pp. 1-25.

Lievesley, Geraldine (2009), "Is Latin Americs moving left-towards? Problems and prospects”. En: Liesvesley, Geraldine y Ludlam, Steve, Reclaiming Latin America. Experiments in radical social democracy, Zed Books, London.

Liesvesley, Geraldine y Ludlam, Steve (2009), Reclaiming Latin America. Experiments in radical social democracy. Zed Books, Londres.

López-Maya, Margarita (2003), “Movilización, institucionalidad y legitimidad en Venezuela”, en Revista Venezolana de Economía y Ciencias Sociales, Vol. 9, $\mathrm{N}^{\circ}$ 1, pp. 211-226.

López Maya, Margarita y Lander, Luis (2010), “Venezuela 2009: En medio de dificultades avanza el modelo socialista del Presidente Chávez”. En Revista de Ciencia Política, n², pp. 537-553.

López Maya, Margarita y Panzarello, Dinolis Alexandra (2012), “Populismo, rentismo y socialismo del siglo XXI: el caso venezolano”. En: Cheresky, I., ¿Qué democracia en América Latina? Prometeo y Clacso, Buenos Aires.

Luna, Pablo y Filgueira, Fernando (2009), “The left turns as Multiple Paradigmatic Crises”. En: Third World Quarterly, pp. 371-395.

Macdonald, Laura y Ruckert, Arne (2009), Post-Neoliberalism in the Americas. Palgrave Macmillan, U.K.

Machado, Juan Carlos (2008), “Ecuador: hasta que se fueron todos...”, en Revista de Ciencia Política, Vol. 28, º 1, pp. 89 -215.

Mayorga, Fernando (2009), Antinomias. El azaroso camino de la reforma 
política, CESU, Cochabamba.

Mignolo, Walter (2006), “Evo Morales en Bolivia: ¿giro a la izquierda o giro descolonial?”. J. da Cruz. Democracias en Desconfianza. Ensayos en sociedad civil y política en América Latina, Editorial Coscoroba, Montevideo.

Moncagatta, Paolo y Safranoff, Ana (2013), “¿Quién apoya a la izquierda 'populista' latinoamericana”. En Revista Mexicana de Análisis Político y Administración Pública, pp. 29-48.

Moreira, Carlos, Raus, Diego y Gómez Leyton, Juan Carlos (2008), La nueva política en América Latina. Rupturas y continuidades. Ed. Trilce. Montevideo.

Muñoz María Antonia y Martín Retamozo (2009), "Hegemonía y discurso en la Argentina contemporánea. Efectos políticos de los usos de "pueblo" en la retórica de Néstor Kirchner”. En Revista Perfiles Latinoamericanos. FLACSO-México, México.

Negretto, Gabriel (2009), “Paradojas de la Reforma Constitucional en América Latina”. En Journal of Democracy en español, pp. 38-54.

Novaro, Marcos (2011a), "Decisionismo transicional y programático en Argentina y América Latina”. En Diálogo político, n² 2, pp. 201-226.

Observatorio Social de América Latina (2012), “Movimientos socioambientales en América Latina”. N³2, CLACSO, Buenos Aires.

Panizza, Francisco (2008), "Fisuras entre Populismo y Democracia en América Latina”. En Stockholm Review of Latin American Studies, pp. 81-93.

Ídem (2009), “Nuevas izquierdas y democracia en América Latina”. En Revista CIDOB d'afers internacionals, pp. 78.88.

Paramio, Ludolfo (2003), "Perspectivas de la izquierda en América Latina”. En: Real Instituto Elcano de Estudios Internacionales y Estratégicos. http:/ /www.realinstitutoelcano.org/documentos/37/37.pdf

Ídem (2008), “El regreso del Estado: entre el populismo y la regulación”. Conferencia Plenaria en el XIII Congreso del CLAD, Buenos Aires.

Poulantzas, Nicos (1976), Las clases sociales en el capitalismo actual. Siglo XXI Editores. México

Quiroga, Virginia (2010), “Somos nosotros. Somos gobierno. Experiencia de movimientos sociales en Bolivia. En Revista de Estudios Bolivianos, s/p.

Ramírez Gallegos, Franklin (2006), “Mucho más que dos izquierdas”, en Nueva Sociedad, $\mathrm{n}^{\circ}$ 205. Pp. 30-44. 
Ídem (2007), “’Posteneoliberalismo' y 'neodesarrollismo': ¿las nuevas coordenadas de acción política de la izquierda latinoamericana?”. En Revista La Tendencia, pp. 51-56.

Ídem (2010a), "Postneoliberalismo indócil. Agenda pública y relaciones socio-estatales en el Ecuador de la Revolución Ciudadana”. En Revista Temas y Debates, $\mathrm{N}^{\circ}$ 20, Universidad Nacional de Rosario, CLACSO, pp. 175-194.

Ídem (2010b), “Decisionismos transformacionales, conflicto político y vínculo plebeyo. Poder y cambio en la nueva izquierda sudamericana”, en América Latina. 200 años y nuevos horizontes, VV.AA, Secretaría de Cultura de la Nación, Buenos Aires: pp.131-157.

Ídem (2012a), “Crisis neoliberal y reconfiguraciones estatales: Ecuador y la heterodoxia sudamericana”, en Revista Línea Sur Vol. 1, Issue 2, pp. 84104.

Ídem (2012b), “Reconfiguraciones estatales en Ecuador: 1990-2011”. En Thwaites Rey, M. (Ed), El Estado en América Latina: continuidades y rupturas. Ed. Arcis, Santiago de Chile.

Ídem (2013), "El proceso constituyente ecuatoriano y sus dilemas de legitimidad. Un contrapunto andino”, Perspectivas constitucionales comparadas, Universidad de Bologna, Bologna: (en prensa).

Retamozo, Martín y Muñoz, María Antonia (2013), “Kirchnerismo y hegemonía. Política y gobierno”. En Peronismos, izquierdas y organizaciones populares. EDULP, La Plata.

Reynoso, Diego (2008), “La brecha entre mayorías institucionales y preferencias ciudadanas en los gobiernos pos Consenso de Washington. En: Moreira et al, La nueva política en América Latina: Rupturas y continuidades. FLACSO Uruguay, UNLa, U-Arcis y Trilce, Montevideo.

Rodríguez Garavito, César, Barrett, Patrick y Chávez, Daniel (2008), The Latin American Left: Utopia Reborn, Pluto Press, Londres.

Roberts, Kenneth (2007), "Repoliticizing Latin America: the revival of populist and leftist alternatives”. En Woodrow Wilson Center Update on the Americas. http://www.wilsoncenter.org/sites/default/files/ repoliticizing.roberts.lap.pdf

Rovira Kaltwasser, Cristóbal (2011), “Toward post-neoliberalism in Latin America?”. En Latin American Research Review, pp. 225-234.

Sader, Emir (2008), Posneoliberalismo en América Latina. Clacso, Buenos Aires. 
Stefanoni, Pablo (2006), El nacionalismo indígena en el poder. OSAL, pp. 37-44

Ídem (2012), “Comparación del futuro de la democracia entre Venezuela, Bolivia y Ecuador”. En Dargatz, A. y Zuazo, M., Democracias en transformación. ¿Qué hay de Nuevo en los nuevos Estados andinos? FES- ILDIS, La Paz.

Stokes, Susan (2009), “Globalization and the Left in Latin America”. En h t t p : / / w w w. yale.edu/macmillanreport/resources / Stokes_GlobalizationLeft.pdf

Svampa, Maristella (2005), La sociedad excluyente. La Argentina bajo el signo del neoliberalismo. Taurus, Buenos Aires.

Ídem (2006), “Movimientos sociales y nuevo escenario regional: las inflexiones del paradigma neoliberal en América Latina”. En Revista Sociohistórica, pp. 141-155.

Ídem (2008), “Argentina: una cartografía de las resistencias (2003-2008)”. $O S A L, \mathrm{~N}^{\circ}$ 24: pp. 17-49.

Svampa, Maristella y Antonelli, Mirta (2009), Minería transnacional, narrativas del desarrollo y resistencias sociales. Biblos, Buenos Aires.

Tapia, Luis (2009), La coyuntura de la autonomía relativa del Estado. Clacso y Muela del Diablo editores, La Paz.

Thwaites, Rey (2009), “Después de la globalización neoliberal: ¿Qué Estado en América Latina?”. En OSAL, Número 27: pp. 19-43.

Ídem (2012), El Estado en América Latina: continuidades y rupturas. Ed. Arcis, Santiago de Chile.

Touraine, Alain (2006), “Entre Bachelet y Morales, ¿existe una izquierda en América Latina?”. En Nueva Sociedad, pp. 46-54.

Van Cott, Donna Lee (2005), From Movements to Parties in Latin America. The Evolution of Ethnic Politics. Cambridge University Press, Nueva York.

Viciano, Roberto y Martínez Dalmau, Rubén (2011), “El nuevo constitucionalismo latinoamericano: fundamentos para una construcción doctrinal”. En Revista General de Derecho Público Comparado. º 9.

Vilas, Carlos. (2006), “The Left in South America and the Resurgence of National-Popular Regimes”. En Hershberg E. y Rosen F.,”. The New Press / NACLA, Nueva York.

Ídem (2010), “Las ‘ideas y regresos’ del Estado”. En Utopía y praxis lati- 
noamericana, $\mathrm{N}^{\circ}$ 49: pp. 101-108.

Weyland, Kurt (2009), “The rise of Latin America's Two Lefts: insights from Rentier State Theory”. En Comparative Politics, pp. 145-164.

Wylde, Christopher (2011a), Latin America After Neoliberalism. Developmental Regimes in Post-Crisis States. Palgrave Macmillan.

Ídem (2011b), “State, Society and Markets in Argentina: The Political Economy of Neodesarrollismo under Néstor Kirchner, 2003-2007”. En Bulletin of Latin American Research, pp. 436-445.

Recibido: 15.10.2014

Aceptado: 20.11.2014 